\title{
The impact of age on prognosis in patients with gastric cancer: experience in a tertiary care centre
}

\author{
Maan El Halabi ${ }^{1,2}$, Renee Horanieh ${ }^{1}$, Hani Tamim $^{3}$, Deborah Mukherji ${ }^{1,4}$, Sara Jdiaa ${ }^{1}$, Sally Temraz $^{1,4}$, \\ Ali Shamseddine ${ }^{1,4}$, Kassem Barada ${ }^{1,2}$ \\ ${ }^{1}$ Department of Internal Medicine, American University of Beirut Medical Centre, Beirut, Lebanon; ${ }^{2}$ Division of Gastroenterology, American \\ University of Beirut Medical Centre, Beirut, Lebanon; ${ }^{3}$ Clinical Research Institute, American University of Beirut Medical Centre, Beirut, Lebanon; \\ ${ }^{4}$ Division of Hematology and Oncology, American University of Beirut Medical Centre, Beirut, Lebanon \\ Contributions: (I) Conception and design: K Barada, M El Halabi, R Horanieh, D Mukherji, A Shamseddine; (II) Administrative support: None; (III) \\ Provision of study materials or patients: K Barada, A Shamseddine, S Temraz, D Mukherji, H Tamim; (IV) Collection and assembly of data: M El \\ Halabi, R Horanieh, S Jdiaa, H Tamim, K Barada; (V) Data analysis and interpretation: M El Halabi, R Horanieh, S Jdiaa, H Tamim, K Barada; (VI) \\ Manuscript writing: All authors; (VII) Final approval of manuscript: All authors. \\ Correspondence to: Prof. Kassem Barada, MD. Division of Gastroenterology, American University of Beirut Medical Centre, P.O. Box 11-0236, Beirut, \\ Lebanon. Email: kb02@aub.edu.lb.
}

Background: Gastric cancer (GC) is a leading cause of cancer-related death in the world and most patients have advanced disease upon presentation. The effect of age on prognosis in GC is controversial. We aimed to determine the impact of age on survival in patients with GC.

Methods: This was a retrospective study of the medical records of Lebanese patients diagnosed with GC at the American University of Beirut Medical Center (AUBMC) between 2005 and 2014. Patients were divided into young ( $<65$ years) and older groups ( $\geq 65$ years). A multivariate analysis was done to determine the independent predictors of survival. Kaplan-Meier method was used for analysis of long-term survival outcomes.

Results: The sample consisted of 156 patients. The mean age was 62.15 (SD 13.54). Most patients presented with stage 4 disease $(62.2 \%)$ and poorly differentiated histology $(66.4 \%)$. The most common symptoms were abdominal pain and weight loss. On bivariate analysis, advanced stage $(\mathrm{P}=0.02)$ and higher grade $(\mathrm{P}=0.04)$ were associated with increased mortality. Patients $<65$ years of age were significantly more likely to have poorly differentiated tumours, while patients $\geq 65$ years had more comorbidities $(\mathrm{P}=0.001)$. The 5 -year DFS were $35 \%$ and $37 \%$ for patients $<65$ years of age and $\geq 65$ years of age, respectively $(\mathrm{P}=0.15)$.

Conclusions: Higher grade and advanced stage are associated with worse survival in patients with GC, but age did not seem to have an impact. Screening high risk patients and early diagnosis are necessary to improve survival.

Keywords: Gastric cancer (GC); prognosis; age

Submitted Mar 07, 2020. Accepted for publication Sep 04, 2020.

doi: 10.21037/jgo-20-139

View this article at: http://dx.doi.org/10.21037/jgo-20-139

\section{Introduction}

According to a recent national epidemiological study and records from the Lebanese Ministry of Health, cancer incidence in Lebanon is among the highest in the region and is expected to remain high over the coming decade (1). Specifically, there was an increase in the age-standardized incidence rates of gastric cancer (GC) between 2003 and 2008, from 6.2 to 8.1 cases per 100,000 among males, and from 5.1 to 6.7 cases per 100,000 among females $(1,2)$. In Lebanon, there are on average 240 cases of GC per year, and GC ranks as the seventh and tenth most common cause of cancer among males and females, respectively (3). 
The outcome of GC is often poor, and even with advancements in diagnosis and treatment, 5-year overall survival (OS) rate for advanced GC is still under 30\% $(4,5)$. This is largely attributed to later age (i.e., between 70 and 75 years of age), and advanced stage at diagnosis $(6,7)$. The association between age and survival in GC, however, is controversial. It has been reported that younger patients diagnosed with GC may have lower survival than older ones (8). However, subsequent studies did not confirm this difference $(8,9)$. In a large study involving 13,840 patients from 17 USA population-based registries of patients diagnosed with metastatic GC, old age ( $>75$ years), male gender and proximal location were significant independent predictors of shorter survival (10). Understanding the association between age and GC survival may affect the global prognosis and increase treatment efficacy $(11,12)$.

To our knowledge, only one study examined the clinical and demographic characteristics of patients with GC in Lebanon (2). However, it did not examine the effect of age on prognosis. The aim of this study was to determine the impact of age on survival in Lebanese patients with GC. We present the following article in accordance with the STROBE reporting checklist (available at http://dx.doi. org/10.21037/jgo-20-139).

\section{Methods}

\section{Study design and setting}

The study is a single institution retrospective cohort study based on chart review of all gastric adenocarcinoma cases treated between January 2005 and December 2014 at the American University of Beirut Medical Centre (AUBMC), a private and tertiary facility that operates 420 beds, serving around 22,000 in-patients per year. AUBMC provides a wide spectrum of medical, nursing, and paramedical training programs at the undergraduate and post-graduate levels in different specialties and subspecialties and is considered a referral medical center in the Middle East region.

\section{Participants}

Participants were patients diagnosed with gastric adenocarcinoma between January 2005 and December 2014. All patients who had other types of GC (e.g., lymphoma, gastrointestinal stromal tumour, carcinoid tumours) were excluded. The list of all patients diagnosed with gastric adenocarcinoma was acquired from the Department of
Medical Records at AUBMC. The initial list included 415 patients. However, 89 patients were excluded for being non-Lebanese, 134 were excluded because of missing data, and 36 patients were excluded because gastric adenocarcinoma was not their primary malignancy. The final list included 156 patients whose data were extracted from the medical records retrospectively.

\section{Study variables}

After acquiring patients' names list from the medical records at AUBMC, hospital medical charts were reviewed for demographic and clinical data. Variables included place/date of birth, gender, residential area, age at diagnosis, body mass index (BMI), history of gastro-oesophageal reflux disease (GERD), H. pylori screening results, smoking and alcohol intake status, use of home medications such as non-steroidal anti-inflammatory drugs (NSAIDs), proton pump inhibitors (PPIs) and iron supplements, family history of GC, personal history of any GI cancer or any radiation exposure, presenting symptoms along with duration of symptoms, and the method of diagnosis. Furthermore, radiographic, endoscopic, surgical, and pathological records were reviewed to obtain data on gross tumour characteristics, histological type, tumor stage and grade, peri-neural and perivascular invasion, number and ratio of positive lymph nodes, and positivity of surgical margins. Other parameters that were included are undertaken treatment options (i.e., curative versus palliative management), the type of surgical intervention, and whether neo-adjuvant, adjuvant, or palliative chemotherapy was administered. The dates of death or last follow up were recorded.

Patients were divided into two groups, namely below or above 65 years of age in order to compare the 2 groups in terms of demographic, clinical, histological data, and management. BMI was categorized in accordance with $\mathrm{WHO}$ standards, namely BMI $<25$ as normal, BMI between $25-30$ as overweight, and BMI $\geq 30 \mathrm{~kg} / \mathrm{m}^{2}$ as obese. We also reviewed the total number of comorbidities which included diabetes, hypertension, cerebrovascular disease or stroke, cirrhosis, heart failure, coronary artery disease, and chronic kidney disease.

\section{Statistical analyses}

The Statistical Package for the Social Sciences (SPSS) version 23.0 was used for data cleaning, management, and analysis. Categorical variables were presented using number and percent, whereas continuous ones were presented 
by mean and standard deviation $( \pm \mathrm{SD})$. In the bivariate analysis, the association between young ( $<65$ years) and old age ( $\geq 65$ years) of patients and other categorical variables was assessed using the Chi-square test, whereas Student's $t$-test was used for the association with continuous variables.

A multivariate logistic regression analysis was performed to determine the predictors of survival. The independent variables chosen for modelling were those found to be significant at the bivariate analysis level in addition to those considered clinically meaningful. The variables included in the model were: age, grade, stage, lympho-vascular invasion, nodal metastasis, number of comorbidities and tumour location. The results were described as odds ratios (OR) and their corresponding $95 \%$ confidence intervals (CI). The probability of survival was analysed using Kaplan-Meier survival analysis with comparison between groups $(<65$ vs. $\geq 65$ years) using log-rank test. $\mathrm{P}<0.05$ was considered statistically significant. In a separate analysis, patients were further subdivided into 3 categories: $<45,45-65,>65$ years of age, and we examined the effect of age, grade, and stage on survival in all three sub-categories.

All procedures followed were in accordance with the ethical standards of the responsible committee on human experimentation (institutional and national) and with the Helsinki Declaration of 1964 and later versions. Approval was obtained from the Institutional Review Board committee at the American University of Beirut (AUB) IM.KB.14. No informed consent was taken from patients since this is a retrospective study that involves reviewing the charts of eligible patients. This is in line with our IRB policy. No identifying information was included in the analysis and review of data.

\section{Results}

\section{Participant characteristics}

The sample consisted of 156 Lebanese patients diagnosed with gastric adenocarcinoma as the primary malignancy from January 2005 until December 2014 at AUBMC. The mean age was 62.15 (SD 13.54), and $53.8 \%$ were males. More than half reported having higher than normal BMI, with $33.3 \%$ being overweight, $15.6 \%$ being obese, and $3.4 \%$ being severely obese.

\section{Patients presentation}

There was a median time of 2 months between the onset of symptoms and the diagnosis. The most common presenting symptoms were upper abdominal pain $(56.6 \%)$, weight loss (44.7\%), nausea/vomiting (28.2\%) followed by GI bleeding $(21.7 \%)$. The mean haematocrit on presentation was low (32.2\%). Using the tumor-node-metastasis (TNM) staging system, most participants $(62.2 \%)$ presented at stage 4 disease and most (66.4\%) had poorly differentiated (high grade) histology. Only 5 patients (3.2\%) were lost to follow-up.

The majority of patients $(62.0 \%)$ had distant metastasis, most commonly to the liver, peritoneum, extra regional lymph nodes, lungs, and the brain. Furthermore, only a minority $(28.0 \%)$ underwent surgical resection, mainly those who were in stages $0,1,2$, and 3, out of whom $33.3 \%$ received neo-adjuvant treatment. For some patients with non-resectable GC, palliative surgery was done to relieve symptoms or complications like bleeding or obstruction. Less than half of the total sample presented without any comorbidities $(43.5 \%)$, whereas the rest presented with 1 to 4 comorbidities. As for the location of the tumor, $29.4 \%$ had a proximal location, while $32.7 \%$ had a distal location and $18.3 \%$ had diffuse type, the rest $19.6 \%$ were in the middle third of the stomach. Finally, almost half of patients who had surgery $(52.2 \%)$ received adjuvant therapy postoperatively (Table 1).

\section{Prognosis of GC in Lebanese patients}

On bivariate analysis, both advanced stage $(\mathrm{P}=0.02)$ and poor grade $(\mathrm{P}=0.04)$ were associated with mortality. Chisquare tests of independence were conducted to examine the relation between age group and other variables (Table 2). Patients $<65$ years of age were significantly more likely to have poorly differentiated (high-grade) histology $(\mathrm{P}<0.001)$, were significantly more likely to have progression of the disease where the cancer becomes more advanced or spreads to different locations $(\mathrm{P}=0.03)$ when compared to patients $\geq 65$ years of age. Severe obesity was more prevalent in patients $>65$ years of age $(\mathrm{P}=0.05)$ and were significantly more likely to have a higher number of comorbidities (Table 2, $\mathrm{P}<0.001$ ).

No statistically significant associations were found between gender $(\mathrm{P}=0.19)$, smoking $(\mathrm{P}=0.32)$, and stage at diagnosis $(\mathrm{P}=0.31)$ between patients below and those above 65 years of age. Kaplan Meir survival curve showed a similar overall survival in the two groups of patients. The 5 -year DFS were $35 \%$ and $37 \%$ for patients $<65$ years of age and $\geq 65$ years of age, respectively $(\mathrm{P}=0.15)$. The overall survival 
Table 1 Clinical characteristics of GC in Lebanese patients

\begin{tabular}{|c|c|}
\hline Clinical characteristics & Total $\mathrm{N}=156, \mathrm{n}(\%)$ \\
\hline \multicolumn{2}{|c|}{ Presenting signs/symptoms $(n=156)$} \\
\hline Upper abdominal pain & $86(56.6)$ \\
\hline Weight loss & $68(44.7)$ \\
\hline Nausea/vomiting & $43(28.2)$ \\
\hline Gastro-intestinal bleeding & $33(21.7)$ \\
\hline Dysphagia & $19(12.5)$ \\
\hline Iron deficiency anemia & $16(10.5)$ \\
\hline Others & $10(6.5)$ \\
\hline \multicolumn{2}{|l|}{ Stage at diagnosis ${ }^{a}(n=111)$} \\
\hline Stage 0 & $1(0.9)$ \\
\hline Stage 1 & $7(6.3)$ \\
\hline Stage 2 & $21(8.9)$ \\
\hline Stage 3 & $13(11.7)$ \\
\hline Stage 4 & $69(62.2)$ \\
\hline \multicolumn{2}{|l|}{ Histology $^{b}(n=134)$} \\
\hline Well differentiated & $6(4.5)$ \\
\hline Moderately differentiated & $39(29.1)$ \\
\hline Poorly differentiated & $89(66.4)$ \\
\hline \multicolumn{2}{|l|}{ Site of metastasis ${ }^{b}(n=134)$} \\
\hline Liver & $30(20.5)$ \\
\hline Peritoneum & $29(20.0)$ \\
\hline Extra-regional LN & $32(22.1)$ \\
\hline Lungs & $9(6.2)$ \\
\hline Others* & $18(12.5)$ \\
\hline \multicolumn{2}{|l|}{ Family history of GC ( $n=121)$} \\
\hline Yes & $8(6.6)$ \\
\hline \multicolumn{2}{|l|}{ Surgical resection $(n=156)$} \\
\hline Yes & $44(28.0)$ \\
\hline
\end{tabular}

*, others: bone, omentum, mesentery, gallbladder, spleen, pancreas; ${ }^{a}$, missing information for $28 \% ;{ }^{b}$, missing information for $14 \%$ of patients. LN, lymph nodes.

after 10 years of diagnosis of GC was $35 \%$ and $18 \%$ for patients $<65$ years of age and $\geq 65$ years of age respectively with a median follow up of 3 years and 4 years respectively (0.51) (Figure 1).

Table 3 presents a multivariate regression analysis of
Table 2 Demographic and clinical characteristics of patients with GC younger or older than 65 years of age

\begin{tabular}{|c|c|c|c|}
\hline \multirow[b]{2}{*}{ Characteristics } & \multicolumn{3}{|c|}{ Age } \\
\hline & $\begin{array}{c}<65 \text { years } \\
(\mathrm{N}=80)\end{array}$ & $\begin{array}{c}\geq 65 \text { years } \\
(N=76)\end{array}$ & $P$ value \\
\hline Age (mean), years old & $51.4 \pm 9.01$ & $73.5 \pm 6.32$ & $<0.0001$ \\
\hline Gender, n (\%) & & & 0.19 \\
\hline Male & $39(48.8)$ & $45(59.2)$ & \\
\hline Female & $41(51.3)$ & $31(40.8)$ & \\
\hline \multicolumn{2}{|l|}{ Body mass index, $\mathrm{n}(\%)$} & & 0.05 \\
\hline Underweight & $7(9.1)$ & $3(4.3)$ & \\
\hline Normal & $28(36.4)$ & $32(45.7)$ & \\
\hline Overweight & $27(35.1)$ & $22(31.4)$ & \\
\hline Obese & $15(19.5)$ & $8(11.4)$ & \\
\hline Severely obese & $0(0.0)$ & $5(7.1)$ & \\
\hline \multicolumn{2}{|l|}{ Smoking ${ }^{a}(n=148), n(\%)$} & & 0.318 \\
\hline Non-smokers & $38(49.4)$ & $43(60.6)$ & \\
\hline Ex-smokers & $11(14.3)$ & $10(14.1)$ & \\
\hline Smokers & $28(36.4)$ & $18(25.4)$ & \\
\hline \multicolumn{3}{|c|}{ Number of comorbidities ${ }^{\mathrm{b}}(\mathrm{n}=155), \mathrm{n}(\%)$} & $<0.0001$ \\
\hline 0 & $62(77.5)$ & $6(8.0)$ & \\
\hline 1 & $16(20.0)$ & $27(36.0)$ & \\
\hline 2 & $2(2.5)$ & 28 (37.3) & \\
\hline 3 & $0(0.0)$ & $11(14.7)$ & \\
\hline 4 & $0(0.0)$ & $3(4.0)$ & \\
\hline \multicolumn{3}{|c|}{ Stage at diagnosis ${ }^{c}(n=111), n(\%)$} & 0.310 \\
\hline Stage 0 & $0(0.0)$ & $1(2.0)$ & \\
\hline Stage 1 & $2(3.3)$ & $5(10.0)$ & \\
\hline Stage 2 & $11(18.0)$ & $10(20.0)$ & \\
\hline Stage 3 & $6(9.8)$ & $7(14.0)$ & \\
\hline Stage 4 & $42(68.9)$ & $27(54.0)$ & \\
\hline \multicolumn{3}{|l|}{ Histology $^{d}(n=134), n(\%)$} & $<0.0001$ \\
\hline Well differentiated & $2(3.0)$ & $4(5.9)$ & \\
\hline $\begin{array}{l}\text { Moderately } \\
\text { differentiated }\end{array}$ & $10(15.2)$ & $29(42.6)$ & \\
\hline Poorly differentiated & $54(81.8)$ & 35 (51.5) & \\
\hline \multicolumn{4}{|c|}{ Progression $^{d}(n=134), n(\%)$} \\
\hline Yes & $36(45.0)$ & $21(27.6)$ & 0.03 \\
\hline
\end{tabular}

Table 2 (continued) 
Table 2 (continued)

\begin{tabular}{lccc}
\hline & \multicolumn{3}{c}{ Age } \\
\cline { 2 - 4 } Characteristics & $\begin{array}{c}<65 \text { years } \\
(\mathrm{N}=80)\end{array}$ & $\begin{array}{c}\geq 65 \text { years } \\
(\mathrm{N}=76)\end{array}$ & P value \\
\hline Location of tumor $^{\mathrm{a}}(\mathrm{n}=143), \mathrm{n}(\%)$ & & 0.19 \\
Proximal & $21(30.4)$ & $25(39.1)$ & \\
Middle third & $9(13.0)$ & $14(21.9)$ & \\
Distal & $30(43.5)$ & $21(32.8)$ \\
Diffused & $9(13.0)$ & $14(21.9)$ &
\end{tabular}

, missing information for $9 \% ;{ }^{b}$, missing information for $1 \% ;^{c}$, missing information for $28 \%$; $^{d}$, missing information for $14 \%$.

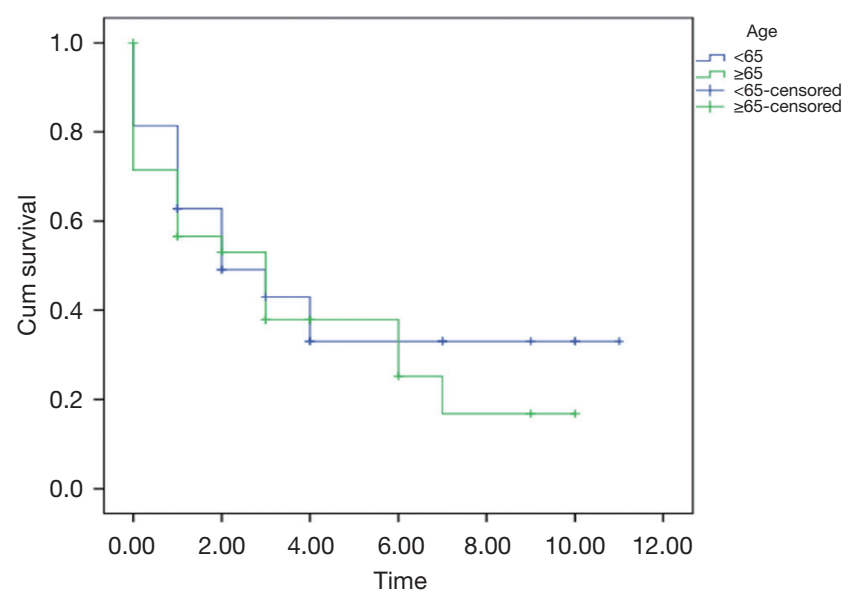

Figure 1 Kaplan-Meir survival curve (in years) of GC patients younger or older than 65 years of age.

Table 3 Multivariate regression: predictors of mortality in GC patients

\begin{tabular}{llc}
\hline Variables & OR $(95 \% \mathrm{Cl})$ & $\mathrm{P}$ value \\
\hline Age & $2.06(0.64-6.71)$ & 0.23 \\
Grade & $3.28(1.02-10.58)$ & 0.05 \\
Stage & $1.93(1.03-3.62)$ & 0.04 \\
\hline
\end{tabular}

Variables included in the model: age (reference: $<65$ years old); grade (reference: well), stage (reference: 0/1/2); nodal metastasis, lympho-vascular invasion, comorbidities, tumour location.

variables that were found to be independent predictors of mortality in our GC population. We found that high grade $(\mathrm{P}=0.05)$ and advanced stage $(\mathrm{P}=0.04)$ are both independent predictors of mortality. Meanwhile, after adjusting for grade and stage, old age was found to have a numerically increased odds ratio for worse survival (OR 2.06, 95\% CI: 0.64-6.71), but this did not reach statistical significance $(\mathrm{P}=0.602)$. Nodal metastasis, lympho-vascular invasion, number of comorbidities and location of tumour were not found to have statistically significant prognostic value. Please see Table 3.

Finally, another analysis was performed to compare survival in young people (less than 45 years of age) and people over 65 years of age. Thus, patients were subcategorized into 3 groups according to age: $<45,45-65$, $>65$ years of age. Analysis of grade and stage as prognostic factors showed that both grade $(\mathrm{P}=0.046)$ and stage $(\mathrm{P}=0.046)$ are independent predictors of mortality, but age had no impact.

\section{Discussion}

Our results suggest that poor grade and advanced stage are both associated with worse survival in GC, but age does not seem to have an effect. GC in our population exhibits aggressive features particularly in young patients $(<65)$, as characterised by poorly differentiated grade. Moreover, most patients present at an advanced stage upon diagnosis. Strikingly, the prevalence of metastasis upon presentation $(66.2 \%)$ in the Lebanese population is more than that reported in resource-limited African countries (27\%) and resource-rich European countries (7\%) (13) and is consistent with what has been reported previously (2). On the other hand, in Japan, and despite elevated rates of GC, as much as $60 \%$ of cases are detected in early stages upon presentation (14).

The prognostic value of age in GC is still controversial. Many studies suggest that prognosis depends on disease stage and not on patient's age, and that the delay in the diagnosis of young patients leads to presentation at advanced disease stages $(15,16)$. Table 4 summarizes the literature regarding the effect of age on survival in GC. Seven out of 10 studies showed an effect of age, with only 2 studies showing worse prognosis in young patients $(15,21)$.

Most studies suggest that young patients present with poorly differentiated histology, signet ring type and more advanced disease $(15,16)$, and our findings agree with that. Furthermore, the prognosis in younger patients who underwent curative resection is relatively better that older patients $(11,17,20)$. This suggests that young patients who have early, or potentially curable GC are likely to survive longer than their older counterparts. As the impact of cancer 
Table 4 Summary of studies about impact of age on mortality in GC patients

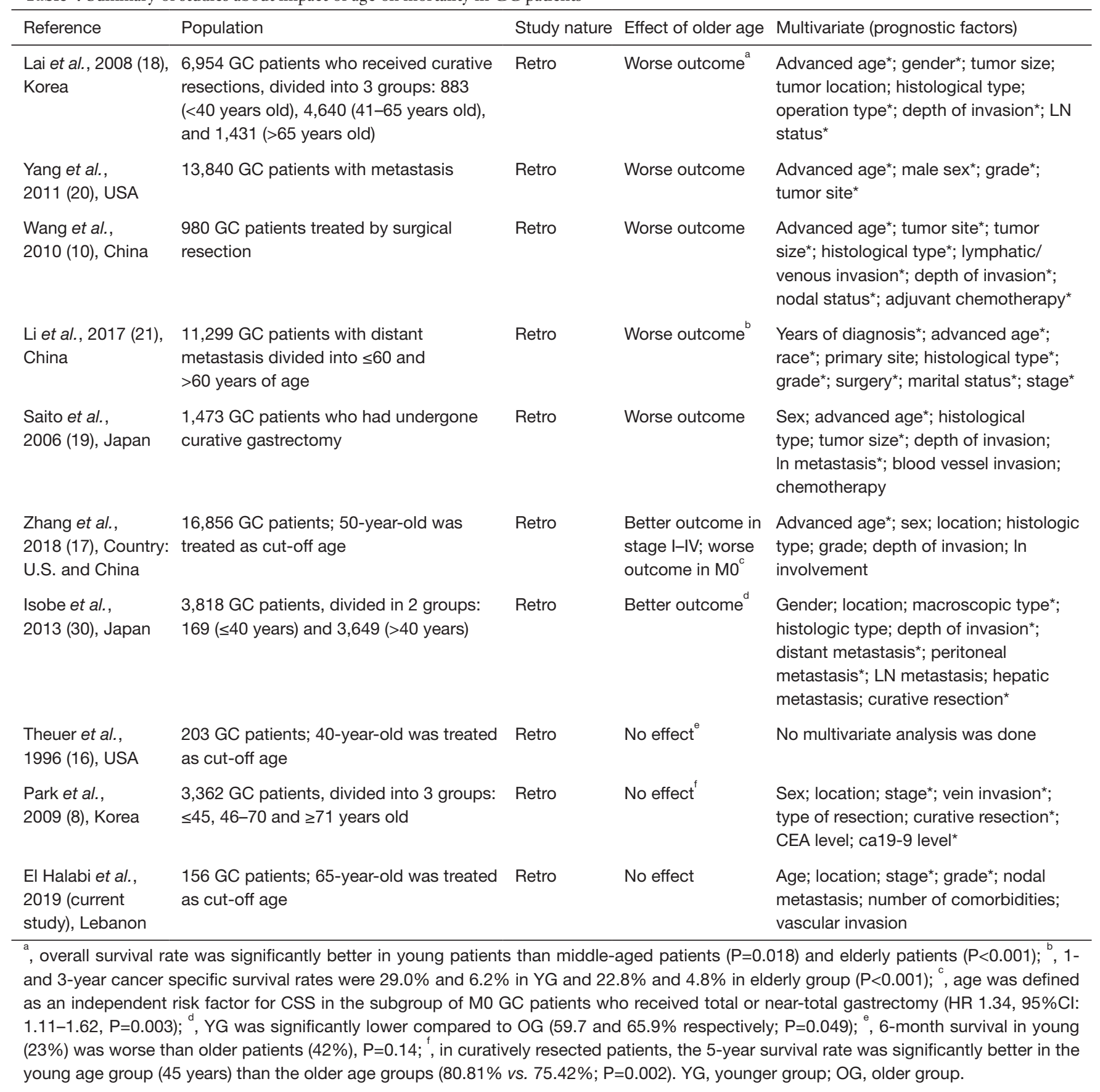

is eliminated, survival will naturally be determined by age and comorbidities and will be longer in younger patients. On the other hand, in patients with advanced metastasis, the prognosis is worse in older patients but is still hideous in both groups (18). Older patients are less likely to tolerate the complications of metastatic disease because of their baseline advanced comorbidities. Notably, no studies have directly addressed the effect of comorbidities on survival in patients with GC. Interestingly, when patients were matched by stage, older patients had lower survival, most likely because of the effect of age and comorbidities on survival, and due to poor tolerance of the elderly to surgery 
and chemotherapy (19). Finally, physicians are naturally more aggressive in the treatment of younger patients, be it surgical or chemotherapy, giving them potentially a survival advantage. In our study, the negative impact of poorly differentiated histology in the young was likely offset by comorbidities in older patients (Table 4).

It is not clear why younger patients are more likely to present with poorly differentiated, diffuse type GC, and whether this could be related to genetic or environmental susceptibility to an aggressive tumour behaviour $(16,21)$. There is typically a time lag between tumour growth and onset of symptoms, but other factors unique to the Lebanese and the Middle Eastern population may have a role in developing aggressive tumour behaviour at a young age (8). In our study, younger patients were more likely to have poorly differentiated histology, which seems to impart a poorer prognosis and lower survival. On the other hand, age, number of comorbidities and tumour location did not show an effect on survival, which may be related to the rapid growth of GC or failure of comorbidities to have enough time to show an impact on mortality. In addition, we might have missed associations due to the relatively small number of patients.

We endorse that a high index of suspicion for the diagnosis in younger patients is necessary to improve prognosis. Therefore, physicians should have low threshold for investigation for GC in patients presenting with unexplained upper gastrointestinal symptoms, symptoms of peptic ulcer that do not improve on medical management, anemia and/or family history of GC $(15,23,24)$. Endoscopic biopsies of gastric ulcers should be conducted for early diagnosis, since this may increase survival $(15,25,26)$. Moreover, unexplained anemia should prompt endoscopic evaluation, particularly when accompanied by upper gastrointestinal symptoms.

Surgical removal of the primary tumour and regional lymph nodes may be the only curative treatment for GC, and early diagnosis and treatment can be potential curative options, particularly in young patients $(17,27)$. Additionally, radiation and chemotherapy may be used as adjunct modalities to improve curative and survival rates, but their role has not been firmly established (28-30).

The most important limitation of this study relates to the data being collected retrospectively from medical record charts without contact with patients. Therefore, selection bias might account for some of our results. Furthermore, the two patient groups were not matched. For example, the younger group had a higher frequency of stage 4 disease, and advanced stage is associated with poor prognosis according to previous studies. The sample size is relatively small (156 cases), and this may decrease the power and generalizability of our findings. Also, this study lacks some important clinical information related to survival such as recurrence rate and type of chemotherapy. In addition, we did not have information on HER2 status. Furthermore, we did not conduct a cause of death analysis. Finally, we did not determine the Charlson Comorbidity Index for our patients; instead, we examined the total number of comorbidities.

\section{Conclusions}

Gastric adenocarcinoma exhibits more aggressive features in younger Lebanese patients when compared to older ones, but younger age seems to have no effect on overall survival. Given that higher tumor grade and advanced stage at diagnosis are associated with worse survival, the significance of young age at diagnosis is unclear and may depend on specific populations and ethnic groups. The results highlight the need for early screening and intervention in high risk Lebanese people. While some observational studies suggest that screening has contributed to detection of cancer in early stages, along with an overall decline in GC mortality, there are no known data from large controlled trials. Since GC survival remains poor, future investigations of the genetic, molecular, and environmental factors underlying these age-related differences may provide important insights and ultimately improve patient survival.

\section{Acknowledgments}

Funding: None.

\section{Footnote}

Reporting Checklist: The authors present the study in accordance with the STROBE reporting checklist. Available at http://dx.doi.org/10.21037/jgo-20-139

Data Sharing Statement: Available at http://dx.doi. org/10.21037/jgo-20-139

Peer Review File: Available at http://dx.doi.org/10.21037/ jgo-20-139

Conflicts of Interest: All authors have completed the ICMJE uniform disclosure form (available at http://dx.doi. 
org/10.21037/jgo-20-139). The authors have no conflicts of interest to declare.

Ethical Statement: The authors are accountable for all aspects of the work and for ensuring that questions related to the accuracy or integrity of any part of the work are appropriately investigated and resolved. All procedures followed were in accordance with the ethical standards of the responsible committee on human experimentation (institutional and national) and with the Helsinki Declaration of 1964 and later versions. Approval was obtained from the Institutional Review Board committee at the American University of Beirut (AUB)_IM.KB.14. No informed consent was taken from patients since this is a retrospective study that involves reviewing the charts of eligible patients. This is in line with our IRB policy. No identifying information was included in the analysis and review of data.

Open Access Statement: This is an Open Access article distributed in accordance with the Creative Commons Attribution-NonCommercial-NoDerivs 4.0 International License (CC BY-NC-ND 4.0), which permits the noncommercial replication and distribution of the article with the strict proviso that no changes or edits are made and the original work is properly cited (including links to both the formal publication through the relevant DOI and the license). See: https://creativecommons.org/licenses/by-nc-nd/4.0/.

\section{References}

1. Shamseddine A, Saleh A, Charafeddine M, et al. Cancer trends in Lebanon: a review of incidence rates for the period of 2003-2008 and projections until 2018. Popul Health Metr 2014;12:4.

2. Assi T, El Rassy E, Khazzaka A, et al. Characteristics of Gastric Cancer in Lebanon: a Descriptive Study from a Single Institutional Experience. J Gastrointest Cancer 2018;49:21-4.

3. Lebanese Ministry of Public Health: National cancer registry - cancer surveillance 2012. Available online: http://www.moph.gov.lb/Prevention/Surveillance/Pages/ Cancer.aspx

4. Lee HJ, Yang HK, Ahn YO. Gastric cancer in Korea. Gastric Cancer 2002;5:177-82.

5. Marqués-Lespier JM, González-Pons $M$, Cruz-Correa $M$. Current Perspectives on Gastric Cancer. Gastroenterol Clin North Am 2016;45:413-28.
6. Wadhwa R, Taketa T, Sudo K, et al. Modern oncological approaches to gastric adenocarcinoma. Gastroenterol Clin North Am 2013;42:359-69.

7. Orditura M, Galizia G, Sforza V, et al. Treatment of gastric cancer. World J Gastroenterol 2014;20:1635-49.

8. Park JC, Lee YC, Kim JH, et al. Clinicopathological aspects and prognostic value with respect to age: an analysis of 3,362 consecutive gastric cancer patients. J Surg Oncol 2009;99:395-401.

9. Nakamura R, Saikawa Y, Takahashi T, et al. Retrospective analysis of prognostic outcome of gastric cancer in young patients. Int J Clin Oncol 2011;16:328-34.

10. Wang W, Li YF, Sun XW, et al. Prognosis of 980 patients with gastric cancer after surgical resection. Chin J Cancer 2010;29:923-30.

11. Anderson WF, Camargo MC, Fraumeni JF, et al. Agespecific trends in incidence of noncardia gastric cancer in US adults. JAMA 2010;303:1723-8.

12. Braga-Neto MB, Carneiro JG, de Castro Barbosa AM, et al. Clinical characteristics of distal gastric cancer in young adults from Northeastern Brazil. BMC Cancer 2018;18:131.

13. Mabula JB, McHembe MD, Koy M, et al. Gastric cancer at a university teaching hospital in northwestern Tanzania: a retrospective review of 232 cases. World J Surg Oncol 2012;10:257.

14. Tan YK, Fielding JW. Early diagnosis of early gastric cancer. Eur J Gastroenterol Hepatol 2006;18:821-9.

15. López-Basave HN, Morales-Vásquez F, Ruiz-Molina JM, et al. Gastric cancer in young people under 30 years of age: worse prognosis, or delay in diagnosis? Cancer Manag Res 2013;5:31-6.

16. Theuer CP, de Virgilio C, Keese G, et al. Gastric adenocarcinoma in patients 40 years of age or younger. Am J Surg 1996;172:473-6; discussion 476-7.

17. 17. Lai JF, Kim S, Li C, et al. Clinicopathologic characteristics and prognosis for young gastric adenocarcinoma patients after curative resection. Ann Surg Oncol 2008;15:1464-9.

18. Yang D, Hendifar A, Lenz C, et al. Survival of metastatic gastric cancer: Significance of age, sex and race/ethnicity. J Gastrointesti Oncol 2011;2:77-84.

19. Li X, Wang W, Ruan C, et al. Age-specific impact on the survival of gastric cancer patients with distant metastasis: an analysis of SEER database. Oncotarget 2017;8:97090-100.

20. Saito H, Osaki T, Murakami D, et al. Effect of age on prognosis in patients with gastric cancer. ANZ J Surg 2006;76:458-61. 
21. Zhang J, Gan L, Xu MD, et al. The prognostic value of age in non-metastatic gastric cancer after gastrectomy: a retrospective study in the U.S. and China. J Cancer 2018;9:1188-99.

22. Isobe T, Hashimoto K, Kizaki J, et al. Characteristics and prognosis of gastric cancer in young patients. Oncol Rep 2013;30:43-9.

23. Buckland G, Agudo A, Luján L, et al. Adherence to a Mediterranean diet and risk of gastric adenocarcinoma within the European Prospective Investigation into Cancer and Nutrition (EPIC) cohort study. J Clin Nutr 2010;91:381-90.

24. Virmani V, Khandelwal A, Sethi V, et al. Neoplastic stomach lesions and their mimickers: spectrum of imaging manifestations. Cancer Imaging 2012;12:269-78.

25. Trédaniel J, Boffetta P, Buiatti E, et al. Tobacco smoking

Cite this article as: El Halabi M, Horanieh R, Tamim H, Mukherji D, Jdiaa S, Temraz S, Shamseddine A, Barada K. The impact of age on prognosis in patients with gastric cancer: experience in a tertiary care centre. J Gastrointest Oncol 2020;11(6):1233-1241. doi: 10.21037/jgo-20-139 and gastric cancer: review and meta-analysis. Int J Cancer 1997;72:565-73.

26. Nomura A, Grove JS, Stemmermann GN, et al. Cigarette smoking and stomach cancer. Cancer Res 1990;50:7084.

27. Crosby DA, Donohoe CL, Fitzgerald L, et al. Gastric neuroendocrine tumours. Dig Surg 2012;29:331-48.

28. Chen K, Xu XW, Zhang RC, et al. Systematic review and meta-analysis of laparoscopy-assisted and open total gastrectomy for gastric cancer. World J Gastroenterol 2013;19:5365.

29. Pretz JL, Wo JY, Mamon HJ, et al. Chemoradtableiation therapy: localized esophageal, gastric, and pancreatic cancer. Surg Oncol Clin N Am 2013;22:511-24.

30. Scartozzi M, Galizia E, Verdecchia L, et al. Chemotherapy for advanced gastric cancer: across the years for a standard of care. Expert Opin Pharmacother 2007;8:797-808. 